\title{
Women's Motivation and Associated Factors for Herbal Medicine Use during Pregnancy and Childbirth: A Systematic Review
}

\author{
Joshua Sumankuuro' ${ }^{10}$, Christabel Soyen², Judith Crockett ${ }^{1}$, Muslim Ibrahim ${ }^{3}$, \\ Frederick Ngmenkpieo, ${ }^{4}$ Joseph K. Wulifan ${ }^{5}$
}

\begin{abstract}
${ }^{1}$ School of Community Health, Faculty of Science, Charles Sturt University, Wagga Wagga, Australia
${ }^{2}$ Public Health Unit, Nadowli District Hospital, Ghana Health Service, Nadowli, Ghana

${ }^{3}$ Department of Gynaecology and Obstetrics, Upper West Regional Hospital, Ghana Health Service, Wa, Ghana

${ }^{4}$ Department of Education, SD Dombo University of Business and Integrated Development Studies, Wa, Ghana

${ }^{5}$ Department of Management Studies, School of Business and Law, SD Dombo University of Business and Integrated Development Studies, Wa, Ghana

Email: joshsumankuuro@gmail.com
\end{abstract}

How to cite this paper: Sumankuuro, J., Soyen, C., Crockett, J., Ibrahim, M., Ngmenkpieo, F. and Wulifan, J.K. (2020) Women's Motivation and Associated Factors for Herbal Medicine Use during Pregnancy and Childbirth: A Systematic Review. Health, 12, 572-597.

https://doi.org/10.4236/health.2020.126044

Received: May 14, 2020

Accepted: June 7, 2020

Published: June 10, 2020

Copyright $\odot 2020$ by author(s) and Scientific Research Publishing Inc. This work is licensed under the Creative Commons Attribution International License (CC BY 4.0).

http://creativecommons.org/licenses/by/4.0/

\begin{abstract}
Background: Herbal medicines use has prevailed over the past decades in both low-middle-income and high-income countries over the years. The use among women has increased with increased risks of ill-health. There is extensive literature on herbal medicine use among women in pre/pregnancy, labour, and the postpartum periods. Therefore, this study aimed to understand women's purposes, experiences, and motivation for using herbal medicines during pregnancy, childbirth and postpartum, and the experiences associated with the use. Methods: Four critical databases were predetermined and searched: CINAHL, Medline, Web of Science, and EMBASE. These databases were chosen for their comprehensiveness and relevance to the review aims. We considered peer-reviewed published articles from January 2000 to December 2018. We chose these databases because we found that they are dominant in the medical and healthcare-related literature. All references were pooled to Endnote reference management software for screening. Quality appraisal of articles was conducted using the Mixed-Method Assessment Tool (MMAT). Content analysis approach was used to extra the data from the articles. Globally, twenty-one articles met the inclusion criteria, and thus, formed the dataset for this review. Results: Most articles $(\mathrm{n}=10,47.6 \%)$ reported solely HM uses on only pregnancy whiles the rest evaluated HM uses in labour, pre-pregnancy, and the postpartum periods. The results have shown that the majority of women received information about HM from friends, family, the "black markets," and drug outlets. Overall, the results were presented in seven
\end{abstract}


broad themes: 1) sociodemographic characteristics of HM users, 2) perceived threat of health problem, 3) sources and quality of the information received, 4) susceptibility to health complications, 5) potential limitations to the use of HM, 6) the motivation for HM utilization, 7) concerns on the combined use of herbal and allopathic medicines. Conclusion: The study recommends the further research into the toxicity of herbal products, to ensure that accurate information can be provided to women before use.

\section{Keywords}

Herbal Medicine, Pregnancy and Childbirth, Maternal Outcomes, Obstetric Complications, Women's and Newborn Health

\section{Introduction}

Improving maternal health outcomes has faced substantial challenges across the globe. Research shows an estimated $99 \%$ of maternal deaths occur in low and middle-income countries [1]. The World Health Organization (WHO) to that effect identified; postpartum hemorrhage, pre/eclampsia, septic shocks, and sepsis, as the major contributors to maternal mortalities [1] [2]. Pharmaceutical (allopathic) medicines are known to be useful for treating maternal health complications, managing labour induction, and for helping improve the overall health outcome of the mother and the foetus [3]. Also, WHO recognizes the importance of herbal medicines use in treating illnesses among member states and supports the use of medicinal plants and plant products. The 1978 Alma-Ata declaration reinforces this relevance [4] [5], and this is reflected in the increase in the use of herbal medicines globally [4] [6]. This is mainly because it has been perceived as natural and safe [7] [8]. According to the WHO, herbal medicine is described as "... herbs, herbal materials, herbal preparations, and finished herbal products that contain as active ingredients parts of plants, or other plant materials, or combinations" [5].

Globally, herbal medicine (HM) or complementary and alternative medicine (CAM) or traditional medicine (TM) intake among women ranges from 45 to $80 \%$ [9]. The World Medicines Situation report for 2011 estimated between 70 to 95\% of people in low and middle-income countries (LMICs) use HM [5]. In some developing countries, traditional medicine (TM) is much more available than allopathic medicine. In most low- and middle-income countries, HM users and herbal dealers outnumber allopathic or conventional medicine intake [7] [10] [11]. Moreover, allopathic practitioners are located primarily in cities or other urban areas. So, for many rural populations, $\mathrm{HM}$ is the only available source of health care.

Herbal medicine ( $H M)$ in this review is a term for the use of seeds, berries, roots, leaves, bark, or flowers of a plant for medicinal purposes. Ginger, cranberry, valerian, raspberry, peppermint, thyme chamomile, sage, aniseeds, fenu- 
greek, green tea, and garlic were the most commonly used herbal products [4] [8] [10]; by women, especially during pregnancy and labour [4]. More significant proportions of women in both advanced and less advanced countries administered such medications during preconception, labour and the postpartum, and for self-termination of unwanted conceptions [12] [13]. For instance, in China, herbal medicine accounts for approximately $50 \%$ of total medicine consumption [8]. The highest reported rate of herbal use medicines was in Russia, accounting for about $69 \%$ of medicine use among the population [4] [5].

Similarly, Kennedy and colleagues [4] found about $52 \%$ and $44 \%$ of herbal medicine use in pregnancy among women in Eastern Europe and Australia, respectively. In a review of studies in nine countries in the Middle East, Hall et al. [10] posit that the prevalence of HM use during pregnancy ranged from about $23 \%$ to $82 \%$. In the advanced or high-income countries (HICs), prevalence estimates of herbal medicine use in pregnancy vary considerably, ranging from 52\% - 58\% in Australia and the United Kingdom to 40\% - 48\% in Norway and Italy [4] [14]. However, herbal medicine in pregnancy and birth was less used in Canada and US, accounting for only about 6\% - 9\% in Canada and the US [14].

Although many herbs are considered safe during pregnancy, some are not [9]. Recent studies have found a significant association between herbal medicine consumption and maternal and neonatal outcomes, such as miscarriage, spontaneous abortion, complicated labour, stillbirths, and neonatal deaths. The low awareness about the possible side-effects of some herbs during pregnancy, combined with the fact that natural herbs and vitamin supplements whose safety may not be authenticated by the appropriate country regulators could increase the risks of unwarranted sequelae [15] [16].

\subsection{The Objective of the Review}

The study explored women's purposes, experiences, and motivation for using herbal medicine during pregnancy, childbirth, and postpartum and experiences associated with the use.

\subsection{Research Question}

Two specific questions motivated this study:

1) What are the perceived benefits and adverse impacts associated with herbal medicine use in pregnancy, labour, and the postpartum stages of maternal health?

2) What motivated women to utilise herbal uterotonics during pregnancy, childbirth, and the postpartum?

\section{Methods}

\subsection{Search Criteria}

First, data was obtained from a search in four databases: CINAHL, Medline, Web of Science, and EMBASE from January 2000 to December 2018. These da- 
tabases were chosen for their comprehensiveness and relevance to the review objective. Maternal health and herbal medicine use discourses received more considerable attention within the search period, especially in less advanced countries. The references of included studies were also tracked for additional papers. Search words and terms were combined with the Boolean operators AND or OR, which narrowed and widened the search, respectively. Some were shortened to capture various relevant suffixes of a term for maximum coverage. Speech marks were used if it was necessary to keep multiple words together as a single search term to further ensure relevance. The search used the terms, "Herbal Medicine," OR "traditional medicine" OR "herbal uterotonics" OR "Complementary and Alternative Medicine" OR "herbal medicine" OR "experiences" OR "experience" OR "motivation" OR "adverse outcomes" OR "reasons" OR "benefits". At the second stage, we searched for "pregnancy," OR "childbirth," OR "delivery" OR Pregnancy Complications", AND "Maternal Health Outcome*". Overall, searches were conducted using both free texts and medical subject headings. All database search was conducted from September to December 2019.

Studies were screened through a two-stage process. First, the imported publications from the searched databases were assessed against; 1) primary research papers of either qualitative, quantitative and mixed methods; 2) must be explicitly on "herbal medicine", "Complementary and Alternative Medicine" and for "pre/pregnancy", "labour or birth or delivery", "postpartum"; 3) written in English, 4) published in peer-reviewed journals'; 5) be written in English; and 6) have full text. Secondly, articles that met the first set of criteria were screened for quality (Table 2).

\subsection{Definition of Inclusion Criteria}

Studies were included if they reported findings in preparation for pregnancy, promoting fertility, treating pregnancy-related problems, used to induce or assist labour, to terminate a pregnancy (abortion), to maintain general wellbeing during pregnancy or postnatal wellbeing. Studies were also included if they described the views, attitudes, or beliefs of women towards TM. The search strategy included primary research (quantitative, qualitative, randomised control studies, and mixed methods studies). Studies that reported combined use of TM and pharmaceuticals were included. We excluded grey literature, unpublished reports, commentary, and perspectives. Studies were excluded if they focused on CAM, HM, or general use of HM without recourse to maternal health. All abstracts were reviewed to identify those articles that addressed HM use and maternal health or women's health as a significant concept, and references of each article were hand-searched for additional eligible studies. Opinion pieces, reports, editorials, seminal works, and systematic reviews were excluded in this review. Articles examining HM use in pre-pregnancy, pregnancy, labour, and the postnatal seeking to improve maternal health outcomes but not peer-reviewed 
were also excluded [Figure $1 \&$ Table 1].

For example, studies that reported TM use for general maternal health complaints and complications such as postmenopausal symptoms, breast cancer, herbal treatments for electroconvulsive shock (ECS) -induced memory deficits [17], Herbal Medicines for Gastrointestinal Disorders in Children and Adolescents [18], and related research articles [19] [20] were excluded. The screening procedure is shown in the Preferred Reporting Items for Systematic Reviews and Meta-Analyses (PRISMA) chart [Table 1].

\subsection{Quality Assessment and Reporting of the Dataset}

All references were pooled to Endnote reference management software for screening. Quality appraisal of eligible studies was assessed the study design, study aim,

Table 1. Full text screening criteria.

\begin{tabular}{|c|c|}
\hline Inclusion & Exclusion \\
\hline $\begin{array}{l}\text { 1) Study conducted on herbal medicine, } \\
\text { herbal uterotonics or complementary and } \\
\text { alternative medicine use in pre/pregnancy, } \\
\text { labour, postpartum. } \\
\text { 2) Qualitative, quantitative, and mixed } \\
\text { methods and are explicitly primary studies. } \\
\text { 3) Must be published in a peer-reviewed } \\
\text { journal. } \\
\text { 4) Must be explicitly on "herbal medicine", } \\
\text { "herbal uterotonics," "traditional medicine" } \\
\text { use in "pre/pregnancy," "labour or birth or } \\
\text { postpartum". } \\
\text { 5) Must have full text accessible and free to } \\
\text { download. } \\
\text { 6) All study designs. }\end{array}$ & $\begin{array}{l}\text { 1) Not focused on "herbal medicine" or "herbal } \\
\text { uterotonics" and "pregnancy, labour/birth, and the } \\
\text { postpartum/postnatal". } \\
\text { 2) Literature reviews, case reports, clinical trials, and } \\
\text { unpublished works. } \\
\text { 3) Documents and articles on herbal medicine or } \\
\text { complementary and alternative medicine in general. } \\
\text { 4) Commentaries, reviews, quantitative studies, } \\
\text { articles in a non-peer reviewed journal, laboratory } \\
\text { reports, thesis or dissertations, and reports of activity } \\
\text { implementation were excluded. } \\
\text { 5) Excluded if the full text was inaccessible. } \\
\text { 6) Does not address pre-conception, pregnancy, } \\
\text { labour, postpartum components of maternal health. }\end{array}$ \\
\hline
\end{tabular}

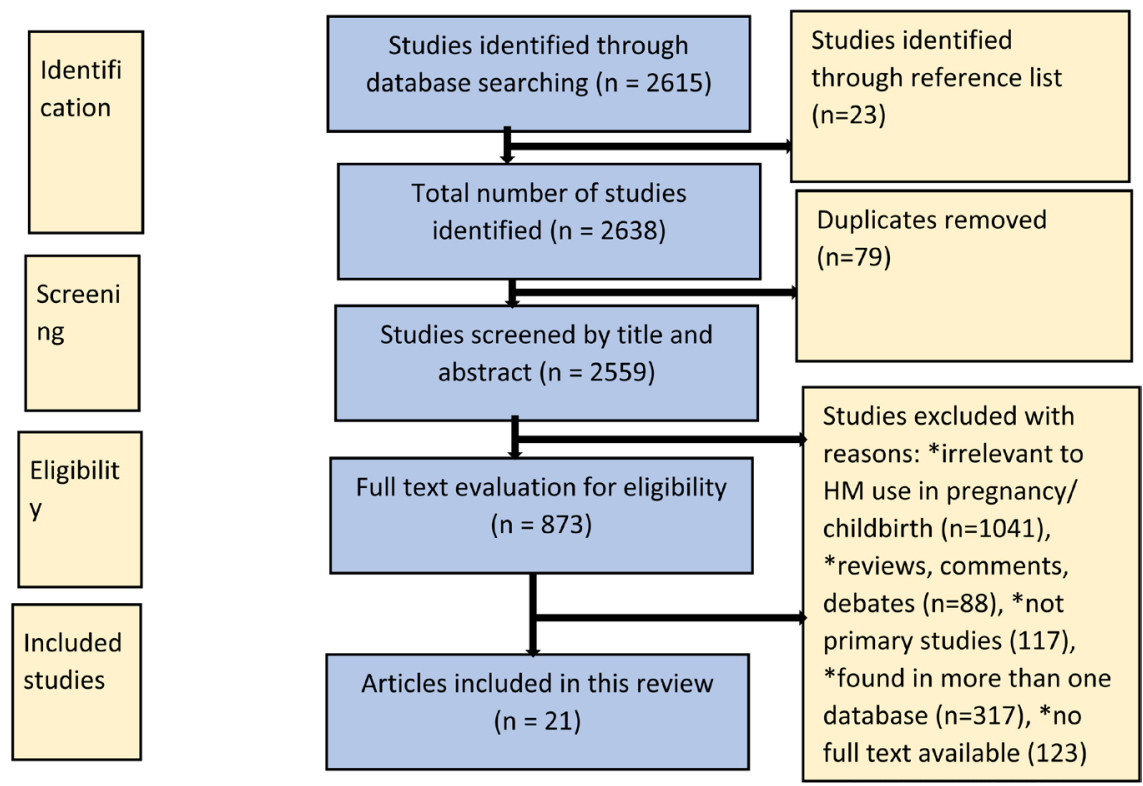

Figure 1. PRISMA Flow chart. 
sampling procedure of all included studies, role of confounding factors for potential bias, and potential generalizability of findings. This process was conducted using the Mixed Method Appraisal Tool (MMAT) [21], for all eligible qualitative, quantitative, and mixed methods studies [22]. The MMAT was used to assess the quality of the identified papers. This quality assessment tool was found to have a moderate to perfect inter-rater reliability score [23].

The tool was designed to assess the quality of articles that were conducted with qualitative, quantitative, and mixed methods designs [21]. There are four quality assessment criteria for quantitative studies and three criteria for qualitative, and the quality of each study was determined by counting the asterisks $\left({ }^{*}\right)$ assigned, according to the set criteria. For mixed methods studies, the premise was that the overall quality of a combination would not exceed the quality of its weakest component [22]. Two reviewers completed this process, and where there were discrepancies, a team of reviewers intervened to resolve it. To optimise objectivity in the quality appraisal process, review articles of eligible studies were not included in the assessment. Using the MMAT appraisal approach, the overall quality score for mixed-methods designs was the lowest score of the study components [22] [23]. The findings of the quality appraisal of eligible studies were reported in Table 2.

Table 2. Result of quality appraisal using mixed methods appraisal tool (MMAT).

\begin{tabular}{|c|c|c|c|c|c|}
\hline \multirow[b]{2}{*}{$\begin{array}{c}\text { Quantitative } \\
\text { non-randomized studies }\end{array}$} & \multicolumn{5}{|c|}{ Quality assessment components using MMAT } \\
\hline & $\begin{array}{l}\text { Are participants } \\
\text { recruited in a } \\
\text { way that } \\
\text { minimizes } \\
\text { selection bias? }\end{array}$ & $\begin{array}{l}\text { Are measurements appropriate } \\
\text { regarding the exposure or } \\
\text { intervention and outcomes? }\end{array}$ & $\begin{array}{l}\text { In the groups being } \\
\text { compared, are the } \\
\text { participants } \\
\text { comparable, or do } \\
\text { researchers consider? }\end{array}$ & $\begin{array}{l}\text { Are there complete outcome data } \\
\text { ( } 80 \% \text { or above), an acceptable } \\
\text { response rate ( } 60 \% \text { or above), or } \\
\text { an acceptable follow-up rate for } \\
\text { cohort studies? }\end{array}$ & Total \\
\hline Al-Ghamdi et al., [2017] & * & * & * & * & $4^{*}$ \\
\hline Allaire et al., [2000] & * & * & * & * & $4^{*}$ \\
\hline Bercaw et al., [2010] & & * & * & * & $3^{*}$ \\
\hline Charaf et al., [2015] & * & * & * & * & $4^{*}$ \\
\hline Chaudhry et al., [2011] & * & * & * & * & $4^{*}$ \\
\hline Fakeye et al., [2009] & * & & * & * & $3^{*}$ \\
\hline Holst et al., [2009] & * & * & * & * & $4^{*}$ \\
\hline Hwang et al., [2016] & * & * & * & * & $4^{*}$ \\
\hline Kaadaga et al., [2014] & * & * & * & * & $4^{*}$ \\
\hline Kenedy et al., [2013] & * & * & * & * & $4^{*}$ \\
\hline Louik et al., [2010] & * & * & * & * & $4^{*}$ \\
\hline Mothupi et al., [2014] & * & * & * & * & $4^{*}$ \\
\hline Moussally et al., [2009] & * & * & * & * & $4^{*}$ \\
\hline Nordeng et al., [2011] & * & * & * & * & $4^{*}$ \\
\hline Nordeng et al., [2004] & * & * & * & * & $4^{\star}$ \\
\hline
\end{tabular}




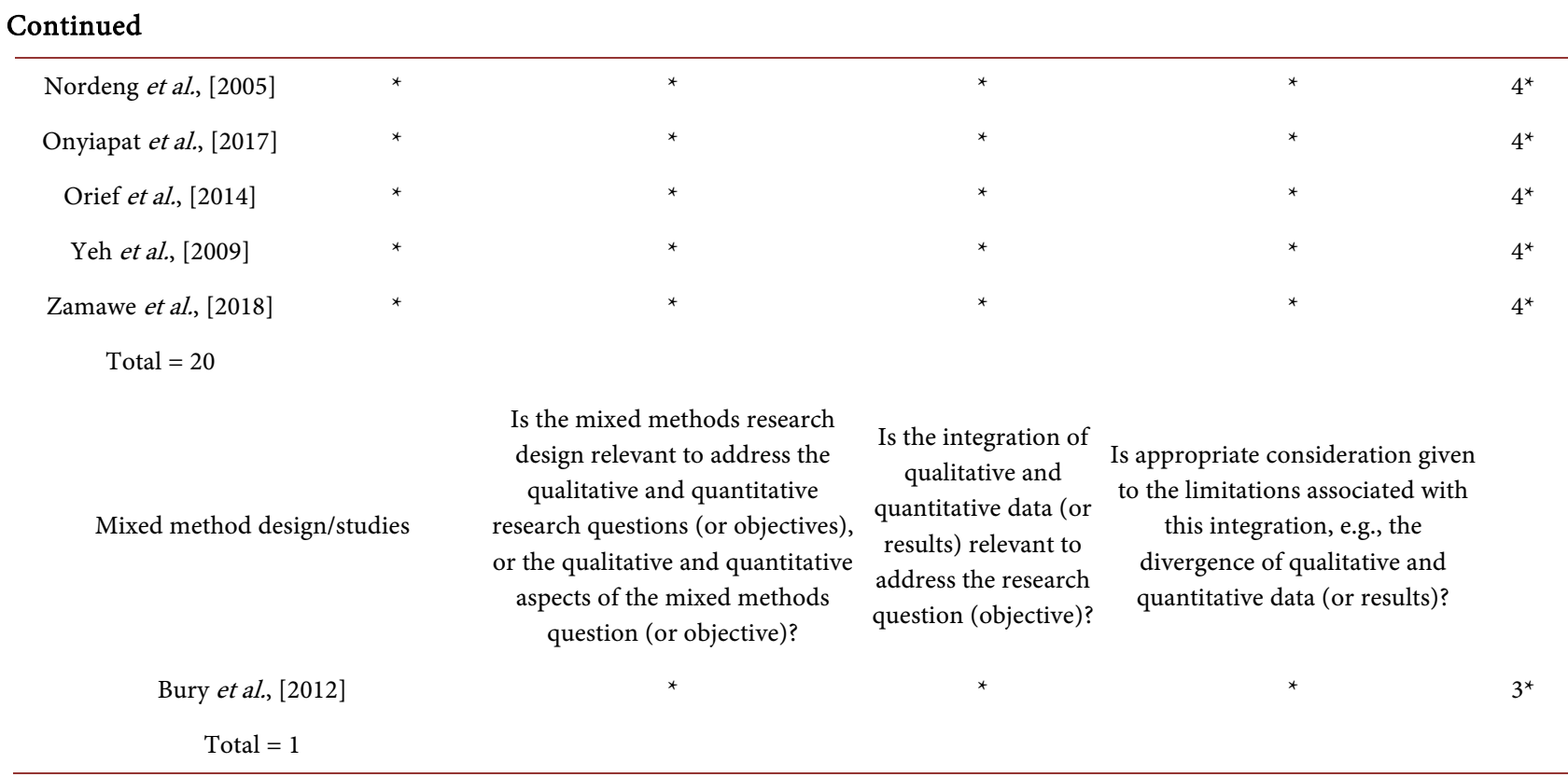

\subsection{Data Synthesis and Analysis}

A narrative synthesis approach was employed to present the findings [21]. In keeping with this framework (Figure 1 \& Table 1), data were reported with an emphasis on highlighting the key and unique factors influencing women's utilisation of herbal medicines during pregnancy, labour and the postpartum stages of maternal health.

Themes were generated using inductive coding procedures concerning the study questions. Deductive codes were based on the research questions [24] [25]. Individual articles were thoroughly read, to identify common patterns and themes based on the predefined and emergent topics. Points of variations and convergence in the eligible studies were highlighted to derive key ideas using a constant comparison approach. Duplicate extraction was completed for $60 \%$ of the included articles, with differences checked by all authors.

To understand the different findings, we adopted the narrative synthesis approach for primary qualitative, quantitative, and mixed methods research (Table $3)$.

\subsection{Data Analysis and Reporting}

A narrative evidence synthesis of studies was undertaken using thematic analysis. During the analysis, a data extraction form was created in Word document using tables. Data extraction was conducted on all 21 articles by authors, using a qualitative approach. Line by line coding and search for related concepts on HM use in pregnancy, childbirth, and the postpartum was conducted for each data set and comparisons made. Any inconsistencies in the data were discussed, and their management agreed upon. We adapted Gibbs framework for data analysis in the process. This began with familiarisation, code building, theme development, and data consolidation and interpretation [39]. Data was analysed independently 
Table 3. Characteristics of included studies - participants, study design, and key findings.

\begin{tabular}{|c|c|c|c|c|c|c|c|}
\hline$S / N$ & Author/s & Setting & $\begin{array}{l}\text { Study design; } \\
\text { data collection } \\
\text { techniques used }\end{array}$ & $\begin{array}{l}\text { Sample size, } \\
\text { participants }\end{array}$ & Study objective & Types of TM used & $\begin{array}{l}\text { Timing of } \\
\text { HM use }\end{array}$ \\
\hline 1 & $\begin{array}{l}\text { Al-Ghamdi } \\
\text { et al., [8] }\end{array}$ & $\begin{array}{l}\text { Saudi Arabia, } \\
\text { urban }\end{array}$ & $\begin{array}{l}\text { A descriptive } \\
\text { cross-sectional; } \\
\text { structured survey }\end{array}$ & $\begin{array}{l}\mathrm{N}=612 \text {, Saudi } \\
\text { pregnant women }\end{array}$ & $\begin{array}{l}\text { determine the prevalence of } \\
\text { herbal medication use during } \\
\text { pregnancy, during labour and } \\
\text { after delivery. }\end{array}$ & Not stated & $\begin{array}{l}\text { Pregnancy, } \\
\text { labour, } \\
\text { post-delivery }\end{array}$ \\
\hline 2 & $\begin{array}{c}\text { Allaire et al., } \\
\quad[26]\end{array}$ & $\begin{array}{l}\text { North Carolina, } \\
\text { US }\end{array}$ & $\begin{array}{l}\text { Quantitative; } \\
\text { Survey }\end{array}$ & $\begin{array}{l}\mathrm{N}=120 \\
\text { nurse-midwives }\end{array}$ & $\begin{array}{l}\text { determine the prevalence and } \\
\text { types of complementary and } \\
\text { alternative medicine therapies } \\
\text { used by certified } \\
\text { nurse-midwives. }\end{array}$ & $\begin{array}{l}\text { Ginger, peppermint, } \\
\text { raspberry leaf, } \\
\text { chamomile, castor oil, } \\
\text { blue cohosh, st john's } \\
\text { wort, valerian, black } \\
\text { cohosh, motherwort, } \\
\text { shepherd's purse, dong } \\
\text { quai, Arnica, comfrey, } \\
\text { alfalfa, garlic }\end{array}$ & $\begin{array}{l}\text { Pregnancy, } \\
\text { labour }\end{array}$ \\
\hline 3 & $\begin{array}{l}\text { Bercaw et } \\
\text { al., [27] }\end{array}$ & $\begin{array}{l}\text { Houston- US, } \\
\text { urban }\end{array}$ & $\begin{array}{l}\text { Quantitative } \\
\text { cross-sectional; } \\
\text { structured survey }\end{array}$ & $\begin{array}{l}\mathrm{N}=485, \text { Hispanic } \\
\text { women in US }\end{array}$ & $\begin{array}{l}\text { investigate the use of herbs, } \\
\text { vitamins, and over-the counter } \\
\text { and prescription medications } \\
\text { among pregnant Hispanic } \\
\text { women and reasons for use }\end{array}$ & $\begin{array}{l}\text { chamomile, garlic, aloe } \\
\text { vera, ginger, Marielito, } \\
\text { Echinacea, blue cohosh, } \\
\text { cod liver oil }\end{array}$ & $\begin{array}{l}\text { Pregnancy, } \\
\text { labour }\end{array}$ \\
\hline 4 & $\begin{array}{c}\text { Bury et al., } \\
\quad[28]\end{array}$ & $\begin{array}{l}\text { Bolivia, both } \\
\text { rural and urban }\end{array}$ & $\begin{array}{l}\text { Qualitative and } \\
\text { quantitative } \\
\text { methods; IDIs, } \\
\text { FGDs, structured } \\
\text { survey }\end{array}$ & $\mathrm{N}=1175$, women & $\begin{array}{l}\text { explore women's experience } \\
\text { of unwanted pregnancy and } \\
\text { induced abortion }\end{array}$ & Not stated & $\begin{array}{l}\text { Pregnancy, } \\
\text { induce } \\
\text { abortion }\end{array}$ \\
\hline 5 & $\begin{array}{c}\text { Charaf et al., } \\
{[13]}\end{array}$ & $\begin{array}{l}\text { Brisbane- } \\
\text { Australia, urban }\end{array}$ & $\begin{array}{l}\text { Quantitative } \\
\text { cross-sectional; } \\
\text { structured survey }\end{array}$ & $\begin{array}{l}\mathrm{N}=412 \text {, women } \\
\text { who had made } \\
\text { their first } \\
\text { antenatal visit }\end{array}$ & $\begin{array}{l}\text { determine the factors } \\
\text { associated with the use of } \\
\text { CAMs by women for } \\
\text { preconception care. }\end{array}$ & $\begin{array}{l}\text { milk thistle, dandelion, } \\
\text { Chinese herbs, ginseng, } \\
\text { Ganoderma (a medicinal } \\
\text { mushroom extract), } \\
\text { guarana, St John's wort, } \\
\text { spirulina, echinacea }\end{array}$ & Pre-pregnancy \\
\hline 6 & $\begin{array}{c}\text { Chaudhry et } \\
\text { al., [12] }\end{array}$ & $\begin{array}{l}\text { Ohio - US; } \\
\text { urban }\end{array}$ & $\begin{array}{l}\text { Quantitative; } \\
\text { structured survey } \\
\text { questionnaire }\end{array}$ & $\mathrm{N}=201$ women & $\begin{array}{l}\text { to identify how frequently } \\
\text { women, attempt to induce } \\
\text { labour through nonprescribed } \\
\text { methods, and what factors are } \\
\text { associated with the use of } \\
\text { such methods }\end{array}$ & Not stated & $\begin{array}{l}\text { Labour } \\
\text { induction }\end{array}$ \\
\hline 7 & $\begin{array}{c}\text { Fakeye et al., } \\
\text { [29] }\end{array}$ & $\begin{array}{l}\text { Nigeria; urban/ } \\
\text { peri-urban, rural }\end{array}$ & $\begin{array}{l}\text { Quantitative; } \\
\text { structured survey, } \\
\text { l face-to-face } \\
\text { interviews }\end{array}$ & $\begin{array}{l}\mathrm{N}=595 \text { pregnant } \\
\text { women }\end{array}$ & $\begin{array}{l}\text { the use of herbal medicines, } \\
\text { safety on usage, knowledge of } \\
\text { potential effects of herbal } \\
\text { remedies on the foetus and } \\
\text { potential benefits or harms } \\
\text { that may be derived from } \\
\text { combining herbal remedies } \\
\text { with conventional therapies }\end{array}$ & $\begin{array}{l}\text { infusions of Camellia } \\
\text { Sinensis (tea), }\end{array}$ & Pregnancy \\
\hline 8 & $\begin{array}{l}\text { Louik et al., } \\
\quad[30]\end{array}$ & $\begin{array}{l}\text { Boston } \\
\text { University, US; } \\
\text { urban }\end{array}$ & $\begin{array}{l}\text { Quantitative' } \\
\text { structured surveys }\end{array}$ & $\begin{array}{l}\mathrm{N}=4866 \text { mothers } \\
\text { of nonmalformed } \\
\text { infant }\end{array}$ & $\begin{array}{l}\text { antenatal herbal and natural } \\
\text { product use among mothers } \\
\text { of nonmalformed infants in } 5 \\
\text { geographic centres. }\end{array}$ & $\begin{array}{l}\text { echinacea, arnica, ginger, } \\
\text { raspberry, valerian, } \\
\text { gingko biloba, Metabolife } \\
\text { [Metabolife International, } \\
\text { Inc., San Diego, CA], } \\
\text { ginseng, chamomile, } \\
\text { cranberry juice, } \\
\text { acidophilus, fish oil, } \\
\text { evening primrose oil }\end{array}$ & $\begin{array}{l}\text { Pregnancy, } \\
\text { labour, } \\
\text { postpartum }\end{array}$ \\
\hline
\end{tabular}




\section{Continued}

9

Norfolk an

[31] University Hospital, UK; urban

$10 \begin{gathered}\text { Hwang et } \\ \text { al., [32] }\end{gathered}$

1 Kaadaaga et Uganda; rural

Europe, North

12

Kennedy et and South

al., [4] America, and

Australia; urban

13 Mothupi Kenya; urban

14 Moussally et Canada; urban al., [35]

Nordeng

15 and Havnen Norway; urban [36]

Nordeng

16 and Havnen Norway; urban

[37]

Registry

Quantitative;

women

Quantitative;

structured survey women
Quantitative,

multinational $\quad \mathrm{N}=9459$ study

Quantitative

methods;

Quantitative; $\quad \mathrm{N}=578$ pregnant

structured survey women

Quantitative

cross-sectional;

structured survey, $\mathrm{N}=335$ pregnan

face-to-face

women

interviews

Quantitative

cross-sectional; $\quad \mathrm{N}=260$ women

structured survey

structured and

semi-structured

$\mathrm{N}=333$ women

receiving ANC

interviews/survey
1) describe the use and the user of herbal remedies

during pregnancy

2) study the sources of

ginger, cranberry, and

raspberry leaf, valerian,

St. John's wort, horsetail

Pregnancy, information about herbs used

to gain insights into the

prevalence and factors leading

to the use of CAM among

pregnant women

black seed chamomile,

cinnamon, castor oil Pregnancy

plant, ginger

to determine the prevalence

and factors associated with

herbal medicine use by

Not stated

Pre-pregnancy

women attending the

infertility clinic.

to determine the prevalence

of herbal medicine, use in

pregnancy and factors related to such use across

participating countries and

regions. The secondary aim

was to investigate who

Motherwort, centaury, lovage cowberry, Uva ursi,

Pregnancy

recommended the use of herbal

medicines in pregnancy

to determine the pattern of

use of herbal medicine in an

urban setting, where women Not stated

have relatively high access to

public healthcare.

1) measure the prevalence of herbal product (HP) use, alone, and concomitantly with prescribed medications

$\mathrm{N}=8505$ women

Quantitative; selected from the structured surveys Quebec Pregnancy

during pregnancy, 2) identify

the most frequently

Not stated

Pregnancy

consumed HP during gestation and 3) determine predictors of HP use at the beginning of pregnancy, and during the third trimester

echinacea, iron-rich

$\mathrm{N}=400$ early

postpartum

investigate the impact of

$\mathrm{N}=400$ early

postpartum herbs, ginger, ginseng

parsley, chamomile, cranberry

valerian, ginkgo, horsetail, sage,

dandelion, bearberry,

hops, lemon balm

Pregnancy socio-demographic factors,

knowledge, and attitude on

the use of herbal drugs in

pregnancy.

herbs, and ginger 


\section{Continued}

\begin{tabular}{|c|c|c|c|c|c|c|c|}
\hline 17 & $\begin{array}{l}\text { Nordeng et } \\
\text { al., [14] }\end{array}$ & Norway; Urban & $\begin{array}{l}\text { Quantitative; } \\
\text { structured surveys }\end{array}$ & $\begin{array}{l}\mathrm{N}=600 \text { pregnant } \\
\text { women }\end{array}$ & $\begin{array}{l}\text { to investigate the use of } \\
\text { herbal drugs by pregnant } \\
\text { women about concurrent use } \\
\text { of conventional medications, } \\
\text { delivery, and pregnancy } \\
\text { outcome }\end{array}$ & $\begin{array}{l}\text { ginger, iron-rich herbs, } \\
\text { echinacea, cranberry, } \\
\text { raspberry leaves, and } \\
\text { chamomile }\end{array}$ & $\begin{array}{l}\text { Pregnancy, } \\
\text { labour }\end{array}$ \\
\hline 18 & $\begin{array}{c}\text { Onyiapat et } \\
\text { al., [9] }\end{array}$ & $\begin{array}{l}\text { Enugu, Nigeria; } \\
\text { Urban }\end{array}$ & $\begin{array}{l}\text { Descriptive study; } \\
\text { structured survey }\end{array}$ & $\begin{array}{l}\mathrm{N}=396 \text { pregnant } \\
\text { women }\end{array}$ & $\begin{array}{l}\text { to obtain information on the } \\
\text { use of Complementary and } \\
\text { Alternative Medicine among } \\
\text { pregnant women. }\end{array}$ & $\begin{array}{l}\text { Herbal mixtures, herbal } \\
\text { tea "mvuruinu," olive } \\
\text { oil, traditional external } \\
\text { cephalic version, folk } \\
\text { remedies, prayer/faith } \\
\text { healing, vision and } \\
\text { pregnancy ritual }\end{array}$ & Pregnancy \\
\hline 19 & $\begin{array}{l}\text { Orief et al., } \\
\qquad[38]\end{array}$ & $\begin{array}{l}\text { Alexandria, } \\
\text { Egypt }\end{array}$ & Quantitative & $\begin{array}{l}\mathrm{N}=300 \text { pregnant } \\
\text { women }\end{array}$ & $\begin{array}{l}\text { to elucidate the use of herbal } \\
\text { medicines in pregnant } \\
\text { women and to explore } \\
\text { patterns of herbal medication } \\
\text { use including dietary } \\
\text { supplements in pregnant } \\
\text { women }\end{array}$ & $\begin{array}{l}\text { Ginger } \\
\text { Peppermint Fenugreek } \\
\text { Green tea Garlic } \\
\text { Aniseed }\end{array}$ & Pregnancy \\
\hline 20 & $\begin{array}{l}\text { Yeh et al., } \\
\quad[7]\end{array}$ & $\begin{array}{l}\text { Taiwan; urban, } \\
\text { rural }\end{array}$ & $\begin{array}{l}\text { Quantitative; } \\
\text { secondary analysis } \\
\text { of National Health } \\
\text { Insurance } \\
\text { Research Database }\end{array}$ & $\begin{array}{l}N=196350 \text { wom- } \\
\text { en }\end{array}$ & $\begin{array}{l}\text { evaluate the patterns of } \\
\text { traditional Chinese medicine } \\
\text { (TCM) use among pregnant } \\
\text { women in the National } \\
\text { Health Insurance program in } \\
\text { Taiwan }\end{array}$ & $\begin{array}{l}\text { Not stated/not } \\
\text { applicable }\end{array}$ & Pregnancy \\
\hline 21 & $\begin{array}{l}\text { Zamawe et } \\
\text { al., [15] }\end{array}$ & Malawi, rural & $\begin{array}{l}\text { Quantitative } \\
\text { (randomised } \\
\text { control trial) } \\
\text { cross-sectional of } \\
\text { secondary } \\
\text { household data }\end{array}$ & $\mathrm{N}=8219$ births & $\begin{array}{l}\text { assess the associations } \\
\text { between self-reported use of } \\
\text { Mwanamphepo (a group of } \\
\text { herbal medicines commonly } \\
\text { used to induce or hasten } \\
\text { labour) and adverse maternal } \\
\text { and neonatal outcomes }\end{array}$ & $\begin{array}{l}\text { Mwanamphepo } \\
\text { (cissus/vitaceae plants } \\
\text { species) }\end{array}$ & $\begin{array}{l}\text { Labour } \\
\text { induction }\end{array}$ \\
\hline
\end{tabular}

and coded by four researchers. The process involved prolonged engagement with the data with regular checks. The codes and concepts were harmonised while unrelated concepts/codes that did not translate to the dominant factors identified, synthesis was then undertaken as an interpretive, inductive process.

\section{Results}

The search generated 2,638 articles. Seventy-nine (79) duplicates were removed, and the titles and abstracts of remaining papers were screened. A total of 873 full texts were screened, and 21 papers were included in the review (Figure 1). The reference list of included papers was checked for potentially eligible articles. The exclusion and inclusion criteria are listed in Table 1. Thirty-seven full-text papers could not be retrieved from online sources. However, given the quality of papers included, the likely effect of non-access to full texts, may only add numbers to the included papers because they were in high impact factor journals. Three articles were given a moderate rating under the MMAT quality assessment 
criteria for inadequate reporting [13] [29] [37]. Three had no specific reporting format and explored other components of HM use in maternal health such as infertility [13], knowledge and attitudes towards HM use [29] [37], Thus, articles were downgraded if the content were not explicitly on the aims of the study. The majority of the studies provided content on the analysis framework, premised on the study objectives and thus covered the different reasons, benefits, and effects for HM use in pregnancy or labour or the postpartum components of maternal care [4] [7] [8] [9] [12] [14] [15] [28] [31] [32] [34] [35] [36] [38], and therefore received a strong rating.

In terms of the geographical region of the studies reported in this study, four articles were conducted in sub-Saharan African, [9] [15] [29] [34], 2 in Australia [4] [13], 2 in Asia [7] [28], another four studies were conducted in Europe [14] [31] [36] [37], 3 in North Africa and the Middle East [8] [32] [38], while the remaining five studies were conducted in South and North America [12] [26] [27] [30] [35]. From the components of maternal health reported in the included articles, the majority $(\mathrm{n}=10 / 21,47.6 \%)$ reported solely on pregnancy [4] [7] [9] [29] [32] [34] [35] [36] [37], 5/21 (23.8\%) described HM use in both pregnancy and labour [14] [26] [27] [28] [31], 2/21 (9.5\%) examined HM use in pregnancy, labour and the postpartum phases of the maternal cycle [8] [30], another two (9.5\%) articles reported findings on pre-pregnancy [13] [33], whilst two (9.5\%) articles evaluated HM use in only labour [12] [15] [Table 3].

From health literature, women's health-seeking behaviour is influenced by a person's perception of a threat posed by a health problem, the value associated with actions aimed at reducing the threat and the exposure to, source of and quality of the information received [40]. In all, seven interrelated themes emerged: 1) sociodemographic characteristics of HM users 2) perceived threat of health problem, 3) sources and quality of information received, 4) susceptibility to health complications, 5) potential limitations to the use of HM, 6) the motivation for HM utilisation, 7) concerns on the combined use of herbal and allopathic medicines.

\subsection{Sociodemographic Characteristics of HM Users}

Several factors influenced women's decisions for using HM. While herbal medicine use among mothers was not significantly associated with their sociodemographic characteristics in some countries, both obstetric histories and fundamental demographic factors influenced women's decision-making and the action they took. For example, herbal product users, mostly among Hispanic mothers in the United States, were mostly among younger mothers than non-users [27] [32].

Culturally, native-born mothers were less receptive to over-the-counter medication than foreign-born Hispanic women in the United States [27]. In the same study, over-the-counter medications intake among mothers was more common among educated women than less educated ones [27]. In other research in the US, Hispanic women reported more HM use, compared to Cauca- 
sian women, and the inclusion of a point to the confidence level did not suggest the use of herbal medicine and other natural products could increase over time [30]. The use of HM among pregnant women was found to increase as they grow older in a multistate study in the US [30]. In the same study, women who took decaffeinated coffee or tea were also slightly more likely to use herbal or other natural products in pregnancy and post-delivery [30].

In another study in the US [27], mothers' demographic and obstetric characteristics such as place of birth, education, timely care, history of medical problems, age, and parity (in univariate statistical analysis) found that prescription medication of herbal medicine was more than twice higher among women with a history of medical problems as opposed to those without such problems (aOR $=2.59,95 \%$ CI: $1.59-4.25, \mathrm{p}=0.0001$ ) [33]. In terms of age, older women of about 30 years or more were associated with HM use in Uganda [33].

However, these findings were contrary to those from Australia [13], where research showed that demographic characteristics such as education, employment status, income levels, or marital status were not significant determinants of HM use among women [13]. It was also found that women who sought Medical Specialist care during obstetric abnormality or complications, including fertility problems, were less likely to utilise HM than other women [13]. There was also no difference in maternal outcomes for users and non-users in the same study [13].

\subsection{Perceived Threat of Health Problem}

Most women used herbal medicine/remedies based on the given health condition/diagnosis and accompanying treatment plans [7] [8] [14] [15] [35] [37], and the desire to get over the pain, the complication or if infertility persisted over time [27] [28]. Women felt that using HM to treat the condition would have a substantial impact on their quality of life and birth outcomes, even when noticeable potential side-effects of the medicine were known [10] [11] [12] [29]. For example, women who reported diabetes, weight increase, gastrointestinal complications, bleeding, and urinary tract infections (UTIs) perceived using HM as a better alternative to prescription medication or allopathic medicine [27] [32]. Specifically, HM was a preferred choice and was common among pregnant women who perceived their health status as "average" or "unhealthy". The evidence shows that most pregnant women across the studies use HM to enhance their health status, strengthen their uterus and improve body immunity in the early stages of the pregnancy to avoid complications and reduced labour [30] [32] [33].

Conversely, from the findings from a randomized controlled trial in Malawi reported, HM use in pregnancy, labour, and the postpartum, showed substantial adverse implications on maternal outcomes. For example, mothers who used particular herbs, locally known as Mwanamphepo, a group of herbal medicines commonly used to induce or facilitate labour, had a significant association with 
increased occurrence of maternal morbidity and neonatal mortality than non-users [15]. The chances that neonatal morbidities and mortalities could occur among users of the labour enhancing herbs were approximately $22 \%$ higher than mothers who did not [15]. Another study that solicited women's views on maternal illnesses and medications used from two months through to the end of pregnancy found that HM use was positively associated with increased maternal age [30].

\subsection{The Source and Quality of the Information Received}

The choice of treatment for maternal illness was influenced partly by the source and quality of information on HM women received. However, all of those sources that were not duly authorised to vend and supply and circulate HM products and relevant information left significantly adverse implications on overall health outcomes of users [4] [33]. This means that women who utilised some HM products were most likely influenced by the source they originated and the quality of the information about the products. For studies that indicated the source and quality of information, first, some women decided in-person to use HM in pregnancy, labour, or postpartum [37] [38]. Second, some had initially witnessed others use it or received recommendations from friends, family, healthcare workers (physicians and nurses), internet pharmacies, direct herbs from the bush, or traditional herbalists [29], gave the recommendation to mothers before the decisions to use particular HM. Third, HM was readily available and accessible in HM shops, illegal dealers, herbal shops and clinics [8], and some women capitalised on that to remedy painful health diagnosis [13] [26] [31] [35]. For example, in Nigeria, more than two-thirds of pregnant women reportedly used herbal medicines that were self-prepared or already packaged [29]. Meanwhile, the majority obtained HM from the open markets, road hawkers, herbal shops, pharmacies, direct herbs from the bush, or recommendations from herbalists [29], physicians, and nurses [26] [35]. Similar influence on women's decisions to use HM was reported in a study in Egypt [38]. For instance, a study involving 400 early postpartum women in an urban community in Norway, $39 \%(n=156)$ who used herbs complained of varied harmful outcomes; the most significant determinant for use was as a result of limited information about the herbs used [36]. Additionally, it was found that a higher proportion of women may have used harmful drugs in the first trimester $(20.5 \%$ of 83 women) than the second trimester (15.4\% of 90 ) and $12.6 \%$ of women in the third trimester [36].

However, in some geographical locations, women obtained expert information on HM products, and their appropriate use before the acquisition. For example, women who used HM in Norway and Nigeria (Enugu area), in pregnancy had high knowledge or were familiar with other people who had tremendous knowledge about the herbal products before deciding on the choices made [9] [37]. Overall, women's exposure to the information on HM was found as a significant, influential factor in HM uptake. It must be noted that the influence of 
location on HM use was, however, widespread among women in both rural and urban settings. In the Middle East, women in urban areas with high education and had ready access to maternal healthcare were reported using HM at substantial levels than even rural areas in other countries [8] [34].

\subsection{Susceptibility to Health Complications}

Some HM users documented in the study realised that they were at risks of developing worsening health complications and associated side-effects from using HM [8] [27] [32]. In some studies, it was observed that although some pregnant women had no intentions to use HM, nurses, and midwives recommended known HM products to them to help treat multiple obstetric complaints and discomforts including nausea and vomiting, labour stimulation, perineal discomfort, lactation disorders, postpartum depression, preterm labour, postpartum haemorrhage, labour analgesia, and malpresentation [26], cold, nausea, sleeping problems, constipation, treat chronic illness, to prepare for childbirth labour [4], and to solve bladder problems [30].

However, users prioritised using $\mathrm{HM}$ in the midst of the risks of obstetric complications associated with the use as more relevant [3] [8]. Four groups of women were observed: first, women who were seeking fertility treatment preferred to endure possible risks of HM than to endure the shame of childlessness from community members and spouse families [33]. Second, women who experienced common discomforts such as nausea and vomiting during pregnancy were prone to use alternative medicines, regardless of the effects. Third, those who sought HM, to augment on-going labour, or with postdate pregnancies and seeking to induce delivery, were likely to accept HM recommendations [14] [26].

The findings have shown that most women were bent on using HM to address multiple obstetric problems, yet, some treatment modalities and the herbal products used, were not adequately investigated for their safety in pregnancy in many countries [4] [14] [26] [30]-[35]. An example was reported in Bolivia, where government regulations disallowed the use of some HM products. However, women persisted in using them [28].

\subsection{Potential Barriers to the Use of HM}

HM products were concurrently used with allopathic or orthodox medicines. The concurrent use was found to have dire consequences on the health of pregnant women and the unborn. Countries where HM use was integrated in the mainstream health system such as the US, women had few limitations consulting their physicians on the best possible HM to use [4] [29]. Therefore, women in places like Nigeria, Uganda, and Kenya perceived the non-integration of HM product utilisation as a barrier to seeking education on the different kinds of $\mathrm{HM}$ available and receiving adequate information on the treatment modalities and correct dosages [12] [28] [29]. That aside, countries with weak enforcement of the regulatory frameworks on HM posed threats and barriers to the utilisa- 
tion, because of limited knowledge on the toxicity and plant constituents as well as the potential adverse effects on the use [28] [31]. Previous research in Ohio, the US, had some concerns about the non-publication of herbs and herbal medicines via influential national dailies and magazines, although $\mathrm{HM}$ was integrated into their health system [12]. These had implications on consumers' knowledge about the adverse effects of the medicines. For instance, limited exposure to herbal drugs was the cause of a lack of knowledge and non-use among pregnant women in Taiwan [7].

However, in some places, HM was the most affordable choice, given the widespread health financing challenges women faced. For instance, in most lowand middle-income countries (LMICs), herbal medicines may not be only relatively cheap, dependent on "how much the client has" and sometimes payable in kind [29]. HM was readily available and accessible than conventional medicines. However, a significant barrier was the claims on decisions made. Nevertheless, in the case of Bolivia, social norms were against the intake of contraception, although their increased knowledge of the different methods, which motivated women's use of alternative medical remedies [28]. Disgrace women could potentially experience from community members for wanting family planning pills, coupled with the disapproval of spouses/husbands, were important reasons for using HM.

\subsection{Perceived Benefit and Efficacy of Herbal Medicine}

According to the World Health Organisation (WHO), the increased use of HM and herbal products is was found to have some correlation with the culture and historical norms within which such products first evolved [6]. The literature demonstrates that most herbal medicines that claim to provide effective cures for various diseases lack sufficient evidence for safety, efficacy, and quality requirements. This problem is compounded by the lack of information about appropriate usage provided at the point of supply. This compromises the safe use of HM [6].

In this evaluation, women's confidence in the potency of HM to treat pains, misery, and trauma was an essential determinant in their choices. For instance, in one study, Fakeye and colleagues reported women (22.4\%) believed HM had more significant potential to cure their health problems than conventional medicine. In contrast, $21.1 \%$ perceived HM to be harmful in pregnancy [29]. A few of the women used $\mathrm{HM}$ as part of their culture, while a significant number (19.7\%) utilised HM when conventional medicines failed [29]. In many locations, mothers perceived that HM had the potential to treat multiple illnesses compared to conventional medicines [8] [31] [38]. In rural Uganda, addressing infertility in marriage was the primary motivation for using herbal medicine, and this occurred without sufficient knowledge on the safety and perceived efficacy of the particular HM product [33].

In the US, a study involving 485 Hispanic women found that one in five 
pregnant women (20\%) believed herbs were safer and better at treating ill-health conditions [27]. In the same study, herbs were used to improve general health and to increase energy. A few women (12\%) used herbs for anaemia, allergies, hypertension, and gastrointestinal symptoms [27]. However, in Kenya, mothers used it to treat back pain, toothache, indigestion, and infectious diseases such as respiratory tract infections and malaria [34]. In places like Russia, Europe, and Australia, nausea and cold-related complaints in pregnancy were crucial drivers for the use of herbal medicine in a multi-country study [4]. Similar results to those of Kennedy et al. [4] were obtained in North Carolina [26]. They wished "to do everything they can" to decrease the potentially adverse maternal outcomes.

Relatedly, only about $29 \%$ of women in the survey in Bolivia reported that HM was easy to access to help with abortion care than prescription drugs [28]. Other women chose HM over modern medicines for abortion care due to a general mistrust of the safety, fear of the adverse effects, and substantial doubts of the effectiveness of modern drugs [28]. Such findings were not reported only in Bolivia but in countries like Norway [37], Malawi [15], Taiwan [7], and Nigeria [9]. Also, in a study that explored herbal medicine use among pregnant women attending family health centers in Alexandria, Egypt, found that more than half of the women (about 65\%) reported HM was more effective at relieving problems in pregnancy [38].

\subsection{The Motivation for HM Utilisation}

The studies considered in this report have shown that the final decision about using HM to address specific health problems was influenced by the advice of over-counter-drug dealers, herbalists, physicians, and supportive others. However, the time is taken in deciding to use HM differed considerably depending on women's health needs, information available, and preference. First, the potential risks and benefits of the particular HM used were considered [4] [12] [13] [28] [29]. However, some studies discovered women's personal preferences motivated the choices and decisions made. For example, a study in Australia demonstrated that improving overall maternal outcomes, weight loss before pregnancy were the crucial determinants for using HM [13]. Relatedly, women who used HM in pregnancy and pre/pregnancy were more likely to use the same during labour and after delivery. For example, in Quebec area in Canada; Mousally and colleagues reported that herbal product intake in the third trimester was motivated by prior experience using it in pre-pregnancy and pregnancy [35].

Second, the varied complications women suffer were determinants in the decision-making process. Among 4866 mothers of nonmalformed infants from 1997 to 2005,282 (5.8\%) of those mothers to these infants reported the use of herbal or natural treatments in that research conducted in North America (Canada and US) [30]. 
Moreover, some women made decisions based on their health condition, and the information received about the effectiveness of the medicines [12] [28] [29] [31] [33].

\subsection{Concerns on the Combined Use of Herbal and Allopathic Medicines}

A particularly concerning aspect of HM use among women was about the combined use of conventional medicine and $\mathrm{HM}$, and often failed to inform or obtain expert views about the medicine [32]. Such attitudes were reported in Norway, Nigeria, and the Middle East [8] [14] [29] [32], meanwhile, women in a US study disclosed the combined use to their physician [13]. While guidelines for the use of most HM in pregnancy recommends that women obtain counsel from physicians and caregivers before using HM in the advanced countries [13] [14] [27] [36], and non-compliance was shown in some studies [5] [6] [10]. For example, a study in Norway has revealed that about one-third of the women failed to comply with physician counsel on the grounds of lack of trust in their competence [37].

In Norway, the use of HM and conventional or modern medicines, concurrently, were reported among 600 pregnant women [14]. However, there were adverse implications on the combined use. For example, among these mothers [14], there was a significant association between women who used iron-rich herbs during pregnancy and high birth weights on the one hand and use of raspberry leaves and caesarean delivery $(23.5 \%$ vs. $9.1 \%)$ on the other, among women who used both forms of medicines in that study [14] after controlling for gestational length and maternal age [14].

Some respondents were more concerned about the side effects/contraindications of Western medicine than HM [34]. About $30.4 \%$ of respondents in Nigeria thought that the side effects of some HM could be dangerous [29]. Meanwhile, among the 405 respondents in the same study who had used herbs before and during pregnancy, $18.0 \%$ had experienced some reactions including, dizziness, malaise, headache, and rashes, post-administration of HM [29]. Evidence showed decreased use of HM during pregnancy in Taiwan was partly associated with adverse concerns about previous exposure to HM [7].

\section{Discussion}

Herbal medicine intake in pre/pregnancy, labour, and post-delivery was found to be a standard practice in many countries. There are extensive studies into different uses of HM and the potential health outcomes of use.

Findings from twenty-one eligible studies were extracted and reported in this study [40] [41]. We found that women used herbal medicine in pre-pregnancy, labour and the postpartum. Herbal medicines were mostly used during pregnancy and labour, accounting for approximately $61.9 \%(n=13 / 21)$ of the studies reported. We found that there was a strong interplay of sociodemographic and 
obstetric characteristics of women and HM use. For example, the place women gave birth, residing in a rural area, their age, education, the nature of health care received during pregnancy, history of medical problems, and parity were found to be significantly associated with HM use for the studies from the United States, Iraq, Kenya, Norway, Nigeria, and Uganda [26] [29] [32] [33] [37].

While there were discrepancies in the participants' characteristics and HM use, the differences may partly be explained by socioeconomic levels of families. The rich may consult with their doctor before use or otherwise ensure adequate information about the benefits and side-effects of the product before using it. This was reported in studies in Norway and the United States [14] [27]. It was observed that some of those women perceived they had better knowledge about the HM than the physician/nurses and would persist in using it against medical advice [14] [27]. For this reason, education on the use of HM, including its negative side-effects, is critical for all categories of women, especially in low- and middle-income countries (LMICs).

In terms of obstetric characteristics, both antenatal care (ANC) and non-ANC attendants used HM products. The ANC programme aims to educate, prevent exposure to adverse outcomes, and prepares them for birth [42], yet, HM use was very much associated with increased ANC visits and rampant [33]. It was found that HM use was independent of personal characteristics in only two studies in Saudi Arabia [8] and the United States [27]. In these studies, herbal medicine use was not related to the participants' educational attainment, marital status, and parity [8] [27], which suggest that ANC education must be intensified, and all expectant and postnatal mothers should be given equal attention.

From the results, quite a good variety of reasons were proffered for using HM. First, the perceived severity of the health problem was a strong driver towards HM use. For example, women who used HM to treat infertility, manage weight, anaemia, allergies, hypertension, respiratory tract infection (RTIs), malaria and gastrointestinal [27], among others were keen on getting through the pain and ill-health condition regardless of the adverse effects associated with the particular medicine. However, for most of them, HM was the ideal medicine for solving pregnancy problems and induction of labour as well as treating postpartum complications [29]-[34]. The intake of HM only to solve maternal health problems was associated with women who lived in rural areas [9] [33] [35] [38], and low-income earners [8]. The World Health Organization (WHO) have shown that about two-thirds of women in low-middle-income countries (LMICs) use $\mathrm{HM}$ as their primary source of healthcare, although, some of those products had adverse effects on maternal outcomes [10] [11]. Nevertheless, it was understood women's decisions to use HM was influenced by a variety of factors such as the source and quality of information about the medicine, recommendation by previous users and healthcare workers, and lack of access to appropriate healthcare services.

Therefore, advertisements and inappropriate therapeutic claims by manufacturers/sellers may expose women to HM use, thereby contributing to the mater- 
nal care decision-making process, which potentially created wrong impressions on the efficacy of their products in addressing obstetric problems. For the critical attractions for choosing certain HM products in this study, it was reported that manufacturers provide a broad range of maternal health problems that the said products could treat, which lured users into perceiving that those particular herbal drugs were more productive, cheaper, and safer to use than allopathic medicines. These findings were reported in other locations [2] [3] [43] [44] [45] [46] [47]. For example, in northern Ghana, herbal oxytocin used by traditional birth attendants and herbal healers were perceived to be effective in treating prenatal and delivery problems, which nevertheless led to birth asphyxia, haemorrhage, fistula and a host of maternal problems among users [2] [47]. However, efforts were often not made to consult and obtain the correct counsel from healthcare workers.

Another source of motivation came from recommendation from previous users. It was found that mothers who had used particular HM and perceived it to be effective in addressing certain maternal complications were later discovered to be harmful. This was because the perceived benefits were as a result of undisclosed facts about their efficacy [9] [29]. In all of these concerns about HM, women in less developed countries were more exposed to the potential harm of HM use in pregnancy, labour and the postpartum for a variety of reasons, not just different kinds of chemicals and metals, although undoubtedly important. It is crucial given the systemic maternal health service delivery challenges in less developed regions, to research the adverse outcomes that may be associated with certain products if improving the overall maternal healthcare delivery outcomes in LMICs is a top priority.

Touching on the adverse effects of HM, thirteen articles reported the negative impacts of HM intake and that the use could potentially account for maternal and neonatal morbidity and mortalities. For example, in the trial study in Malawi, it was reported that women who used Mwanamphepo to induce labour, experienced poor delivery outcomes than those who did not use it during labour [15]. The chances of exposure to sickness and death were $22 \%$ higher among HM users during pregnancy and labour than non-users [15]. Similarly, HM use in the first and second trimesters were more likely to cause complications in the pregnancy as it advances into the third trimester, during delivery and the postpartum [36]. In the interim, it is already known that some herbal preparations, mainly those sold "over-the-counter" may contain potentially toxic amounts of heavy metals [6]. The consequences of heavy metals and broadside effects were clearly demonstrated in previous studies as contributing to birth asphyxia, haemorrhage, outright death, and stillbirths among women who used HM to induce labours in Ghana and other LMICs [2], therefore, as part of the campaigns to improve on maternal outcomes, it is necessary to regulate the polarisation and continuous intake of unauthenticated HM products among pregnant women. At best, ANC programme can be used as a window to correct the wrong informa- 
tion, as a way of reducing the uncontrolled consumption of unvalidated (in terms of products safety) HM products, especially in rural and less educated populations.

Interestingly, some mothers combined the use of HM products and allopathic medicine in many of the studies. For example, there was a combined use of Korean HM was reported for women who sought help for previous poor pregnancy and birth outcomes [11]. A particular HM called Anjeonicheon-tang was used alongside essential medicines for women with recurrent miscarriage and signs of haemorrhage such as vaginal bleeding [11]. The finding is consistent with those of previous studies. Notably, ANC medicines were combined with an HM called "mansugo" in the literature in Ghana, and related medicines in the Middle East [10] [42] [48].

Given the concurrent use and the perceived potential of HM products in solving maternal health problems, there is a need for integration into the mainstream healthcare system in countries that have not considered this reality. The integration has enormous benefits as due diligence will be carried out before allowing HM into the health facilities. HM integration has been accomplished in places like the US, which allows physicians and nurses to recommend useful HM to mothers [12] [27]. This is not the case in less advanced settings, and thus, the contraindications and teratogenic potentials of most herbal products are poorly understood [3] [10] [49]. It was further shown that the cumulative harm of the adverse effects of HM use was mostly found among women who combined HM use with conventional medicines. Such behaviours were broadly shown in the studies in Norway, Nigeria, and the Middle [14] [29] [32] [35]. The study found the interplay of multiple variables as contributing to increased and sometimes unhealthy use of HM. Therefore, a synthesis was needed to pin together these issues to support maternal healthcare policy decisions and related health interventions.

\subsection{Implications for Policy and Practice}

Given that primiparous women, younger mothers, and less educated mothers were the most users of HM in pregnancy and labour, the regulatory frameworks and law enforcement agencies need to intensify the monitoring of manufacturers of herbal products as well as traditional healers and traditional birth attendants, especially in LMICs. It was observed that specific Chinese HM was increasingly used by women. However, their perceived safety was not confirmed, and these resulted in avoidable maternal and neonatal morbidities and mortalities [11]. Also, the study has found that about $70 \%$ of pregnant women in a study in the United States, were given over-the-counter herbal medication during admission to treat diabetes and urinary tract infection, meanwhile, later interrogations on the said products revealed that there was insufficient evidence on the safety of those medicines before the sale [27]. Therefore, further research is needed to understand the safety of HM used pregnant women. 
Stakeholders on maternal and neonatal health service delivery systems need to intensify public education and enforce regulations on the use of HM among pregnant women. Given that early mothers were less exposed to the adverse effects of HM use on in pregnancy and birth outcomes, ANC education could be re-tailored to eradicate inaccurate perceptions about the potency of HM in solving their pregnancy and birth complications. This study suggests the healthy integration of the HM clinics with the maternity/ANC departments in the health facilities in LMICs to help regulate mothers' intake of toxic plant products. This is particularly required in LMICs.

\subsection{Limitations and Strengths of Included Studies, and the Review}

This article must be read against the following limitations. The paper was written using references extracted from four central databases conducted in the English Language, which may not be representative of the overall content on HM product use in pre/pregnancy, delivery, and postpartum. Nevertheless, an additional search through the reference list of included studies [Figure 1], potentially minimised the potential for non-inclusion of relevant articles and thereby reduced biases in the dataset. The review captured a diverse group of articles that used different study methodologies, which made it challenging to conduct meta-analysis or check for publication bias of those studies.

Further, the qualitative content analysis approach was adapted to extract the data as contained in the results. This may be criticized due to its potential to bias the analysis and thus, the study findings. However, this was addressed by ensuring a non-biased approach to coding, identification, and categorisation of all instances and dimensions of women's decision-making process on HM use. However, we are confident that the inductive coding process complemented to avoid potential biases.

\section{Conclusions}

The results of this review have presented HM use among women during pre/pregnancy, labour, and postpartum. HM use was observed to be polarised across all the countries, residences, and among the age cohorts of women. Therefore, we are proposing that: first, the health system of the respective countries should assess holistically, by the stakeholders in maternal health and feasibly integrate HM into the mainstream healthcare delivery through broad consultations. This will provide relevant sources and quality of information on HM products as well as give women access to specialist diagnosis of the health condition before HM uptake. Second, there should be due process in the integration and explicit research findings to educate pregnant women on the potential harm of any given herbal products in the market. Less developed countries need regulatory frameworks for HM products to control unauthorized products, from circulating among the population.

We do acknowledge that most articles in this study were quantitative, which 
limits the review from collecting emic perspectives of women who used HM. Given this, along with the methodological variability in existing studies, there is a need to explore HM use in pregnancy, labour, and postpartum using qualitative or mixed-method designs. This will assist policymakers in understanding the contextual issues associated with HM use and maternal outcomes.

\section{Acknowledgements}

JS is a recipient of Charles Sturt University's (CSU) Writing-Up Award (SN: 11533128). However, CSU played no role in the study design, data collection, or decision to submit this report for publication.

\section{Authors' Contribution}

Conceptualization, JS; Data curation, JS, CS, JC, JKW; Formal analysis, JS, CS, JC, FN, IM, JKW; funding acquisition, JS; Investigation, JS, CS, JC, IM, FN, JKW; Methodology, JS, JC; Software, JS, JC, JKW; Visualization, JS, JC, CS; Writing original draft, JS; Review/editing, JS, CS, JC, IM, FN, JKW.

\section{Conflicts of Interest}

The authors declare no conflicts of interest regarding the publication of this paper.

\section{References}

[1] WHO (2019) Maternal Mortality. WHO News/Fact Sheets.

[2] Sumankuuro, J., Crockett, J. and Wang, S. (2017) Maternal Health Care Initiatives: Causes of Morbidities and Mortalities in Two Rural Districts of Upper West Region, Ghana. PLoS ONE, 12, e0183644. https://doi.org/10.1371/journal.pone.0183644

[3] Tripathi, V., Stanton, C. and Anderson, F.W. (2013) Traditional Preparations Used as Uterotonics in Sub-Saharan Africa and Their Pharmacologic Effects. International Journal of Gynaecology \& Obstetrics, 120, 16-22. https://doi.org/10.1016/j.ijgo.2012.06.020

[4] Kennedy, D.A., Lupattelli, A., Koren, G. and Nordeng, H. (2013) Herbal Medicine Use in Pregnancy: Results of a Multinational Study. BMC Complementary and AIternative Medicine, 13, 355. https://doi.org/10.1186/1472-6882-13-355

[5] Lu, Y., Hernandez, P., Abegunde, D. and Edejer, T. (2011) The World Medicines Situation 2011. Medicine Expenditures World Health Organization, Geneva.

[6] Xue, C.C. (2008) Traditional, Complementary and Alternative Medicine: Policy and Public Health Perspectives. Bulletin of the World Health Organization, Geneva, 86, 1-80. https://doi.org/10.2471/BLT.07.046458

[7] Yeh, H.-Y., Chen, Y.-C., Chen, F.-P., Chou, L.-F., Chen, T.-J. and Hwang, S.-J. (2009) Use of Traditional Chinese Medicine among Pregnant Women in Taiwan. International Journal of Gynaecology and Obstetrics. The Official Organ of the International Federation of Gynaecology and Obstetrics, 107, 147-150. https://doi.org/10.1016/j.ijgo.2009.07.024

[8] Al-Ghamdi, S., Aldossari, K., Al-Zahrani, J., Al-Shaalan, F., Al-Sharif, S., Al-Khurayji, H. and Al-Swayeh, A. (2017) Prevalence, Knowledge and Attitudes toward Herbal 
Medication Use by Saudi Women in the Central Region during Pregnancy, during Labor and after Delivery. BMC Complementary and Alternative Medicine, 17, 196. https://doi.org/10.1186/s12906-017-1714-3

[9] Onyiapat, J.-L., Okafor, C., Okoronkwo, I., Anarado, A., Chukwukelu, E., Nwaneri, A. and Okpala, P. (2017) Complementary and Alternative Medicine Use: Results from a Descriptive Study of Pregnant Women in Udi Local Government Area of Enugu State, Nigeria. BMC Complementary and Alternative Medicine, 17, 189. https://doi.org/10.1186/s12906-017-1689-0

[10] Hall, H.G., Griffiths, D.L. and McKenna, L.G. (2011) The Use of Complementary and Alternative Medicine by Pregnant Women: A Literature Review. Midwifery, 27, 817-824. https://doi.org/10.1016/j.midw.2010.08.007

[11] Jo, J., Lee, S.H., Lee, J.M., Lee, H., Kwack, S.J. and Kim, D.I. (2016) Use and Safety of Korean Herbal Medicine during Pregnancy: A Korean Medicine Literature Review. European Journal of Integrative Medicine, 8, 4-11. https://doi.org/10.1016/j.eujim.2015.10.008

[12] Chaudhry, Z., Fischer, J. and Schaffir, J. (2011) Women's Use of Nonprescribed Methods to Induce Labor: A Brief Report. Birth (Berkeley, Calif.), 38, 168-171. https://doi.org/10.1111/j.1523-536X.2010.00465.X

[13] Charaf, S., Wardle, J.L., Sibbritt, D.W., Lal, S. and Callaway, L.K. (2015) Women's Use of Herbal and Alternative Medicines for Preconception Care. The Australian \& New Zealand Journal of Obstetrics \& Gynaecology, 55, 222-226. https://doi.org/10.1111/ajo.12324

[14] Nordeng, H., Bayne, K., Havnen, G.C. and Paulsen, B.S. (2011) Use of Herbal Drugs during Pregnancy among 600 Norwegian Women in Relation to Concurrent Use of Conventional Drugs and Pregnancy Outcome. Complementary Therapies in Clinical Practice, 17, 147-151. https://doi.org/10.1016/j.ctcp.2010.09.002

[15] Zamawe, C., King, C., Jennings, H.M. and Fottrell, E. (2018) Associations between the Use of Herbal Medicines and Adverse Pregnancy Outcomes in Rural Malawi: A Secondary Analysis of Randomised Controlled Trial Data. BMC Complementary and Alternative Medicine, 18, 166. https://doi.org/10.1186/s12906-018-2203-Z

[16] Sumankuuro, J., Asuuri, A., Mikare, M.D., Ngmenkpieo, F., Crockett, J. and Wulifan, J.K. (2020) High School Student's Knowledge, Attitude and Participation in Sexual Health Education in Rural Northern Ghana. Journal of Biosciences and Medicines, 8, 64-83. https://doi.org/10.4236/jbm.2020.85007

[17] Andrade, C., Sudha, S. and Venkataraman, B.V. (2000) Herbal Treatments for ECS-Induced Memory Deficits: A Review of Research and a Discussion on Animal Models. The Journal of ECT, 16, 144-156. https://doi.org/10.1097/00124509-200006000-00006

[18] Anheyer, D., Frawley, J., Koch, A.K., Lauche, R., Langhorst, J., Dobos, G. and Cramer, H. (2017) Herbal Medicines for Gastrointestinal Disorders in Children and Adolescents: A Systematic Review. Pediatrics, 139, e20170062. https://doi.org/10.1542/peds.2017-0062

[19] Alolga, R.N., Fan, Y., Zhang, G., Li, J., Zhao, Y.-J., Lelu Kakila, J., Chen, Y., Li, P. and Qi, L.-W. (2015) Pharmacokinetics of a Multicomponent Herbal Preparation in Healthy Chinese and African Volunteers. Scientific Reports, 5, Article ID: 12961. https://doi.org/10.1038/srep12961

[20] Singh, B.B., Khorsan, R., Vinjamury, S.P., Der-Martirosian, C., Kizhakkeveettil, A. and Anderson, T.M. (2007) Herbal Treatments of Asthma: A Systematic Review. The Journal of Asthma: Official Journal of the Association for the Care of Asthma, 
44, 685-698. https://doi.org/10.1080/02770900701247202

[21] Popay, J., Roberts, H., Sowden, A., Petticrew, M., Arai, L., Rodgers, M., Britten, N., Roen, K. and Duffy, S. (2006) Guidance on the Conduct of Narrative Synthesis in Systematic Reviews. A Product from the ESRC Methods Programme Version 1, b92.

[22] Pluye, P., Gagnon, M.-P., Griffiths, F. and Johnson-Lafleur, J. (2009) A Scoring System for Appraising Mixed Methods Research, and Concomitantly Appraising Qualitative, Quantitative and Mixed Methods Primary Studies in Mixed Studies Reviews. International Journal of Nursing Studies, 46, 529-546. https://doi.org/10.1016/j.ijnurstu.2009.01.009

[23] Pace, R., Pluye, P., Bartlett, G., Macaulay, A.C., Salsberg, J., Jagosh, J. and Seller, R. (2012) Testing the Reliability and Efficiency of the Pilot Mixed Methods Appraisal Tool (MMAT) for Systematic Mixed Studies Review. International Journal of Nursing Studies, 49, 47-53. https://doi.org/10.1016/j.ijnurstu.2011.07.002

[24] Sumankuuro, J. (2018) Paradoxes of Factors Influencing Maternal Health Outcomes in Rural Northern Ghana. Charles Sturt University, Bathurst.

[25] Sumankuuro, J., Crockett, J. and Wang, S. (2018) Sociocultural Barriers to Maternity Services Delivery: A Qualitative Meta-Synthesis of the Literature. Public Health, 157, 77-85. https://doi.org/10.1016/j.puhe.2018.01.014

[26] Allaire, A.D., Moos, M.K. and Wells, S.R. (2000) Complementary and Alternative Medicine in Pregnancy: A Survey of North Carolina Certified Nurse-Midwives. $O b$ stetrics and Gynecology, 95, 19-23. https://doi.org/10.1097/00006250-200001000-00004

[27] Bercaw, J., Maheshwari, B. and Sangi-Haghpeykar, H. (2010) The Use during Pregnancy of Prescription, Over-the-Counter, and Alternative Medications among Hispanic Women. Birth (Berkeley, Calif.), 37, 211-218. https://doi.org/10.1111/j.1523-536X.2010.00408.x

[28] Bury, L., Aliaga Bruch, S., Machicao Barbery, X. and Garcia Pimentel, F. (2012) Hidden Realities: What Women Do When They Want to Terminate an Unwanted Pregnancy in Bolivia. International Journal of Gynaecology and Obstetrics. The Official Organ of the International Federation of Gynaecology and Obstetrics, 118, S4-S9. https://doi.org/10.1016/j.ijgo.2012.05.003

[29] Fakeye, T.O., Adisa, R. and Musa, I.E. (2009) Attitude and Use of Herbal Medicines among Pregnant Women in Nigeria. BMC Complementary and Alternative Medicine, 9, 53. https://doi.org/10.1186/1472-6882-9-53

[30] Louik, C., Gardiner, P., Kelley, K. and Mitchell, A.A. (2010) Use of Herbal Treatments in Pregnancy. American Journal of Obstetrics and Gynecology, 202, e431-e439. https://doi.org/10.1016/j.ajog.2010.01.055

[31] Holst, L., Wright, D., Haavik, S. and Nordeng, H. (2009) The Use and the User of Herbal Remedies during Pregnancy. The Journal of Alternative and Complementary Medicine, 15, 787-792. https://doi.org/10.1089/acm.2008.0467

[32] Hwang, J.H., Kim, Y.-R., Ahmed, M., Choi, S., Al-Hammadi, N.Q., Widad, N.M. and Han, D. (2016) Use of Complementary and Alternative Medicine in Pregnancy: A Cross-Sectional Survey on Iraqi Women. BMC Complementary and Alternative Medicine, 16, 191. https://doi.org/10.1186/s12906-016-1167-0

[33] Kaadaaga, H.F., Ajeani, J., Ononge, S., Alele, P.E., Nakasujja, N., Manabe, Y.C. and Kakaire, O. (2014) Prevalence and Factors Associated with Use of Herbal Medicine among Women Attending an Infertility Clinic in Uganda. BMC Complementary and Alternative Medicine, 14, 27. https://doi.org/10.1186/1472-6882-14-27

[34] Mothupi, M.C. (2014) Use of Herbal Medicine during Pregnancy among Women 
with Access to Public Healthcare in Nairobi, Kenya: A Cross-Sectional Survey. BMC Complementary and Alternative Medicine, 14, 432. https://doi.org/10.1186/1472-6882-14-432

[35] Moussally, K., Oraichi, D. and Bérard, A. (2009) Herbal Products Use during Pregnancy: Prevalence and Predictors. Pharmacoepidemiology and Drug Safety, 18, 454-461. https://doi.org/10.1002/pds.1731

[36] Nordeng, H. and Havnen, G.C. (2004) Use of Herbal Drugs in Pregnancy: A Survey among 400 Norwegian Women. Pharmacoepidemiology and Drug Safety, 13, 371-380. https://doi.org/10.1002/pds.945

[37] Nordeng, H. and Havnen, G.C. (2005) Impact of Socio-Demographic Factors, Knowledge and Attitude on the Use of Herbal Drugs in Pregnancy. Acta Obstetricia et Gynecologica Scandinavica, 84, 26-33. https://doi.org/10.1111/j.0001-6349.2005.00648.x

[38] Orief, Y.I., Farghaly, N.F. and Ibrahim, M.I.A. (2014) Use of Herbal Medicines among Pregnant Women Attending Family Health Centers in Alexandria. Middle East Fertility Society Journal, 19, 42-50. https://doi.org/10.1016/j.mefs.2012.02.007

[39] Gibbs, G.R. (2018) Analyzing Qualitative Data. Vol. 6, Sage, Thousand Oaks.

[40] Maiman, L.A. and Becker, M.H. (1974) The Health Belief Model: Origins and Correlates in Psychological Theory. Health Education Monographs, 2, 336-353. https://doi.org/10.1177/109019817400200404

[41] Rosenstock, I.M. (1974) Historical Origins of the Health Belief Model. Health Education Monographs, 2, 328-335. https://doi.org/10.1177/109019817400200403

[42] Sumankuuro, J., Crockett, J. and Wang, S. (2017) The Use of Antenatal Care in Two Rural Districts of Upper West Region, Ghana. PLOS ONE, 12, e0185537. https://doi.org/10.1371/journal.pone.0185537

[43] Agyei-Baffour, P., Kudolo, A., Quansah, D.Y. and Boateng, D. (2017) Integrating Herbal Medicine into Mainstream Healthcare in Ghana: Clients' Acceptability, Perceptions and Disclosure of Use. BMC Complementary and Alternative Medicine, 17, 513. https://doi.org/10.1186/s12906-017-2025-4

[44] Chandra, K., Einarson, A. and Koren, G. (2002) Taking Ginger for Nausea and Vomiting during Pregnancy. Canadian Family Physician, 48, 1441-1442.

[45] Marcus, D.M. and Snodgrass, W.R. (2005) Do No Harm: Avoidance of Herbal Medicines during Pregnancy. Obstetrics and Gynecology, 105, 1119-1122. https://doi.org/10.1097/01.AOG.0000158858.79134.ea

[46] Saokaew, S., Suwankesawong, W., Permsuwan, U. and Chaiyakunapruk, N. (2011) Safety of Herbal Products in Thailand: An Analysis of Reports in the Thai Health Product Vigilance Center Database from 2000 to 2008. Drug Safety, 34, 339-350. https://doi.org/10.2165/11586590-000000000-00000

[47] Aborigo, R.A., Allotey, P. and Reidpath, D.D. (2015) The Traditional Healer in Obstetric Care: A Persistent Wasted Opportunity in Maternal Health. Social Science \& Medicine, 133, 59-66. https://doi.org/10.1016/j.socscimed.2015.03.046

[48] Tabatabaee, M. (2010) Use of Herbal Medicines during Pregnancy in Parturient Who Attended in Valiasr Hospital in Kazeroon, Fars, South of Iran. Journal of Maternal-Fetal and Neonatal Medicine, 23, 479.

[49] Zhou, L., Liu, L., Liu, X., Chen, P., Liu, L., Zhang, Y., Wu, Y., Pettigrew, J.C., Cheng, D. and Yi, D. (2014) Systematic Review and Meta-Analysis of the Clinical Efficacy and Adverse Effects of Chinese Herbal Decoction for the Treatment of Gout. PLoS ONE, 9, e85008. https://doi.org/10.1371/journal.pone.0085008 


\section{Highlights}

- herbal medicine was used at all age cohorts and geographical locations.

- there is a need for due process to educate mothers using healthcare delivery outlets on the potential harm of any given herbal product in the public domain.

- women's exposure to the information on HM was a significant, influential factor in HM uptake.

- integration of herbal medicine into the mainstream health system could potentially reduce unregulated use and moderation of harm associated with use among women. 